\title{
The Glass Ceramics Pyroxene Composition Synthesized on the Solar Furnace
}

\author{
Mukhammad-Sultan Paizullakhanov, Ilham Atabaev, Shavkat Fayziev \\ The institute of Material Sciences of the scientific production association "Physics-Sun" Uzbekistan \\ Academy of Sciences, Tashkent city Bodomzor street 2-B \\ fayz@bk.ru

\begin{abstract}
The synthesis processes of glass ceramic materials pyroxene composition based on industrial waste tungsten ores processed in the Big Solar Furnace. The influence of the degree of crystallinity of the material on the microstructure and properties of the target material. The optimum combination of glass and crystalline phases to obtain glass-ceramic material diopside structure with predetermined properties - low thermal
\end{abstract} \\ expansion, high heat resistance and durability by varying the microstructure and phase composition.
}

Keywords: glass ceramic materials, the composition pyroxene, diopside, thermal expansion, strength.

It is known that the sintered ceramic material often contains in its crystalline composition (defined chemical compounds, solid solutions, interstitial phase) and amorphous (vitreous or impurity originally existing glassy) phase. The amount of amorphous phase can be up to about $60 \%$. In the development of structural ceramics and instrumental purpose should especially pay attention to the presence of glass phase for the amorphous phase causes degradation, degradation of strength properties of the material [1]. Considerable importance is also the wear resistance of ceramic materials. Analysis shows that the high mechanical strength at high temperatures, the possibility of varying the coefficient of thermal linear expansion characteristic vitrocrystalline material. Crystallites with an average size of 1 micron interconnected glass layer, the content of which is in the range of 10 - $50 \mathrm{wt} . \%$. This structure informs the material increased thermo mechanical properties. The phase composition of the glass-ceramic, including the relationship between the crystalline and glassy phases (degree of crystallinity), the type of the main crystalline phase is determined thermal, electrical, chemical, and other properties of glass-ceramics [2,3]. Therefore, one of the important tasks is to determine the quantity of materials of glass phase and its influence on the properties of glass-ceramic material. This task can be carried out by means of direct and rapid measurement of the reflection coefficient of the material used for the evaluation of the quality of cement, porcelain [4-6]. It is known that the dependence of the reflectance of light from the plasma frequency can be defined as: $\mathrm{R} \approx 1$ $2 \gamma / \omega_{p}$, where $\omega_{p}$ - plasma frequency, $\gamma$ - frequency electron relaxation [7]. The analysis shows that at frequencies $\gamma<\omega<\omega_{p}$ material should reflect incident light. On the other hand these parameters depend on the phase and structural state of the material, and therefore the phase changes should affect the reflection coefficients.

In this paper we studied glass-crystalline materials pyroxene composition synthesized in the Big Solar Furnace, based pyroxene waste. The mineralogical composition of raw materials represented $45 \%$ pyroxene-gedenbergit, $5 \%$ of andalusite, $40 \%$ of calcite and $10 \%$ quartz. These data indicate that the ability to study the crystallization of raw materials, should be high.

Synthesis was performed on glass pattern: pretreatment of raw materials (crushing, grinding) - mixing in a predetermined ratio - shaping - melting - cooling. Castings were prepared from melts obtained at Big Solar Furnace at a density concentrated luminous flux of at least $300-400 \mathrm{~W} / \mathrm{cm}^{2}$. Cooling produced by dropping the melt into water. Best homogeneity was obtained at $350 \mathrm{~W} / \mathrm{cm}^{2}$ current density.

Processed materials (melts) were homogeneous and fully X-ray amorphous (Figure 1), they are not found microinhomogeneity. 


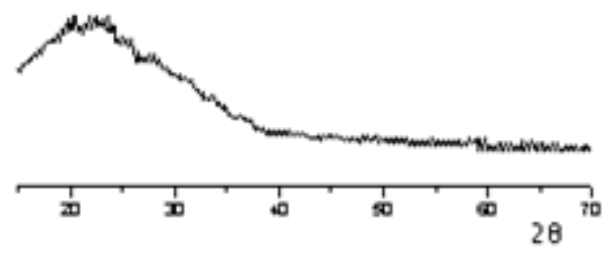

Fig1. X-ray materials, alloy obtained by quenching in water.

Further melts ball milled wet (material: water: grinding media $=1: 1: 1$ ) for 10 hours. Passed through a sieve 005 . The remains have not been used. Glass Sintering conducted at a temperature $1000^{\circ} \mathrm{C}$. The sintered samples had a brown color.

The XRD pattern of the sintered sample detects crystal phase represented by diopside $\mathrm{CaMg}\left(\mathrm{SiO}_{3}\right)_{2}$ (ISTM № - 11-654 diopside) and amorphous glass phase in an amount of 5\%.

Figure 3 shows a micrograph of the sample sintered at $1000^{\circ} \mathrm{C}$. Analysis of the microstructure of the samples showed that they are characterized by fine grain - elongated grain size from 60 to $170 \mathrm{~nm}$, they are tightly packed, slightly oriented (Figure 3 ).

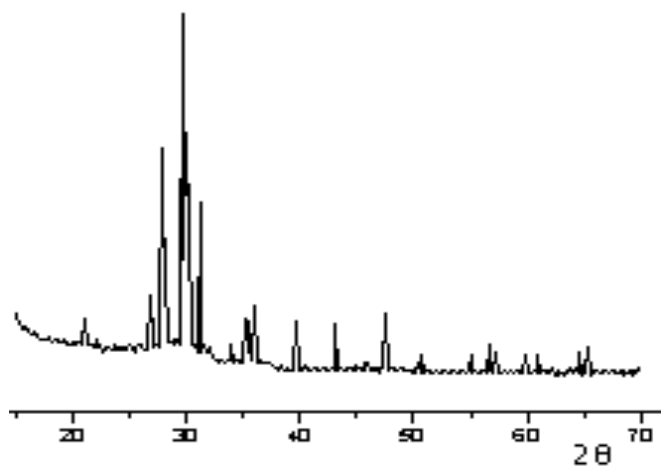

Fig2. The XRD pattern of the sample sintered at $1000^{\circ} \mathrm{C}$

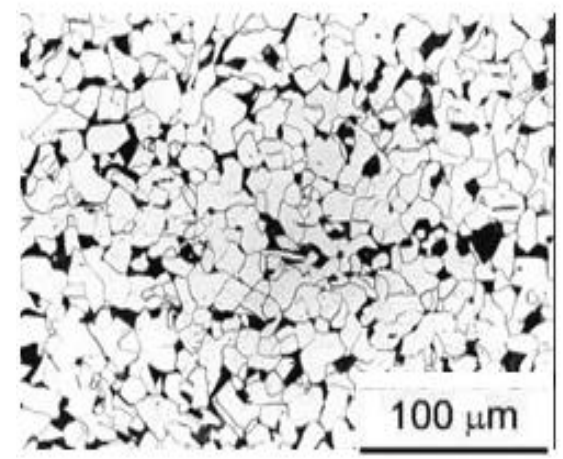

Fig3. The microscopic sample picture, sintered at $1000^{\circ} \mathrm{C}$.

To determine the role of the amorphous and crystalline phases in determining the properties of glassceramic material synthesized in the first step of experiments samples were prepared by adding glass crystalline material in the amorphous silica in an amount of 10, 15, 20, 25, $30 \mathrm{wt} . \%$. The mixture was ball milled the wet process, dried in an oven. Passed through a sieve 005 . The remains have not been used. A force of 1 ton compressed samples in the form of tablets with a diameter of $20 \mathrm{~mm}$. Samples calcined at different temperatures $\left(800,900,1000^{\circ} \mathrm{C}\right)$.

In the fired samples were measured light reflectance using a thermoelectric actinometer registering thermoelectric current proportional to the measured flow of the light radiation reflected from the sample surface.

Figure 4 shows the light reflectance samples pyroxene glass-ceramic depending on the content introduced amorphous phase $\left(\mathrm{SiO}_{2}\right)$.

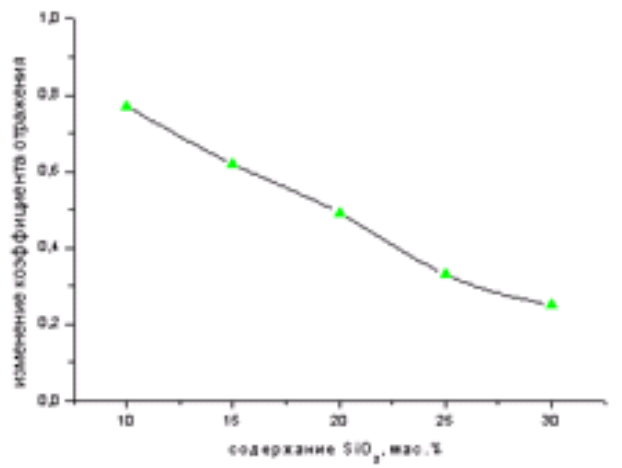

Content of $\mathrm{SiO}_{2}, \%$

Fig4. Light reflectance samples pyroxene glass-ceramic depending on the content of the introduced amorphous phase $\left(\mathrm{SiO}_{2}\right)$. 
Figure 4 shows that with an increase in the content of the glass phase in the glass-ceramic material of light reflectance is reduced. It is known that the amorphous silica has a low absorption and a wide range of light transmittance. On the other hand no transmission indicates the absorption due to multiple refraction at many grain boundaries, the number of which increases with the injected amount of amorphous silica.

Figure 5 shows the variation of the coefficient of retro-pyroxene glass-ceramic samples baked at different temperatures depending on the content introduced amorphous phase ( $\mathrm{SiO} 2)$. With increasing firing temperature (up to $1000^{\circ} \mathrm{C}$ ) a monotonic decrease in the reflection coefficient with increasing amounts of the amorphous phase (Figure 2). Apparently, after firing at temperatures not exceeding $1000^{\circ} \mathrm{C}$ administered silica remains in an amorphous state. It is known that phase transition from amorphous to crystalline silica at temperatures above undergoes $1200^{\circ} \mathrm{C}[8]$.

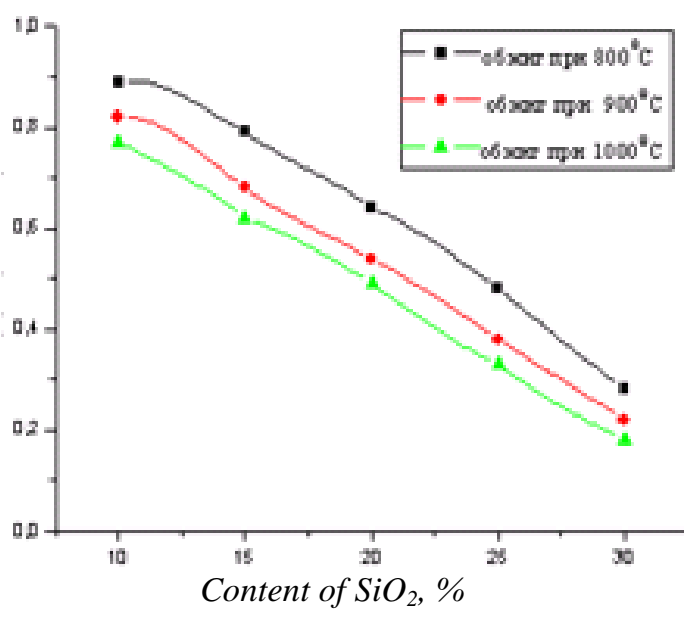

Fig5. Changes in the coefficient of retro-pyroxene glass-ceramic samples baked at different temperatures depending on the content of the introduced amorphous phase $\left(\mathrm{SiO}_{2}\right)$.

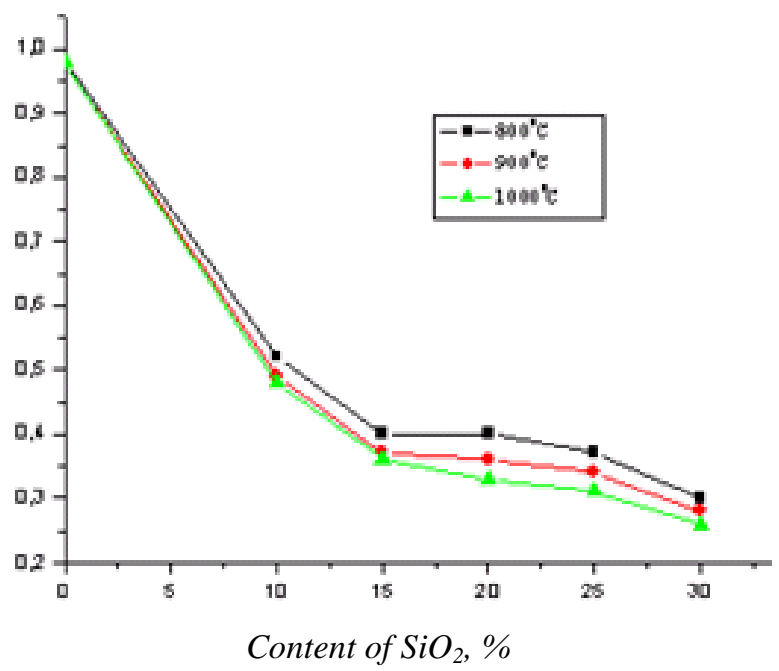

Fig6. Dependence limit strength of the samples calcined at different temperatures on the amount of glass phase.

As seen in Figure 3 with the number of vitreous limit load decreases. This trend is also stored for the samples fired at temperatures of 800,900 and $1000^{\circ} \mathrm{C}$.

Coexistence in the glass material and crystalline phases and their ratio is of course the main factor characterizing the properties of the material. There are two views about the role of these two main phases in the glass-ceramic forming properties. According to the first - the dominant role for the crystalline phase. So after becoming a crystal glass there is improvement in the various properties of the material. On the other hand high strength glass compared with that of crystallized material demonstrates properties that are determined by the properties of the amorphous glass-ceramic, not a crystal phase. It is believed that the carrier is a glass-ceramic properties of the residual glass phase uniformly distributed in intercrystallite space and its composition is determined by the strength, dielectric, thermal, optical, and chemical properties of the glass-ceramic [2]. 
The second phase of experiments samples were prepared by adding a glass crystalline material fused pyroxene solar furnace at $10,15,20,25,30 \mathrm{wt} . \%$. The mixture was ball milled the wet process, dried in an oven. Passed through a sieve 005. The remains have not been used. A force of 1 ton compressed samples in the form of tablets with a diameter of $20 \mathrm{~mm}$. Samples calcined at different temperatures. Character change light reflection coefficient with increasing amounts of vitreous - pyroxene is fused as in the case of adding an amorphous silica to a firing temperature $900^{\circ} \mathrm{C}$. After firing at $900^{\circ} \mathrm{C}$ light reflectance increases to a level of $22 \%$ and a further increase of the firing temperature does not change it. Apparently introduced into glass crystalline material - fused pyroxene, being a glassy state to a crystalline proceeds at a temperature $900^{\circ} \mathrm{C}$ firing. Crystallized grains can combine with the main grain and cause it to increase in size, which is equal to a decrease in the number of grain boundaries, triggering the light absorption material.

In the study of the mechanical properties was found to decrease the compressive strength with increasing amounts of injected melted pyroxene (Figure 7). This is due to the fact that introduced pyroxene during firing at temperatures above $9000 \mathrm{~S}$ becomes crystalline and is soldered with the matrix grain size causing it to rise. This in turn reduces the compressive strength of the material.

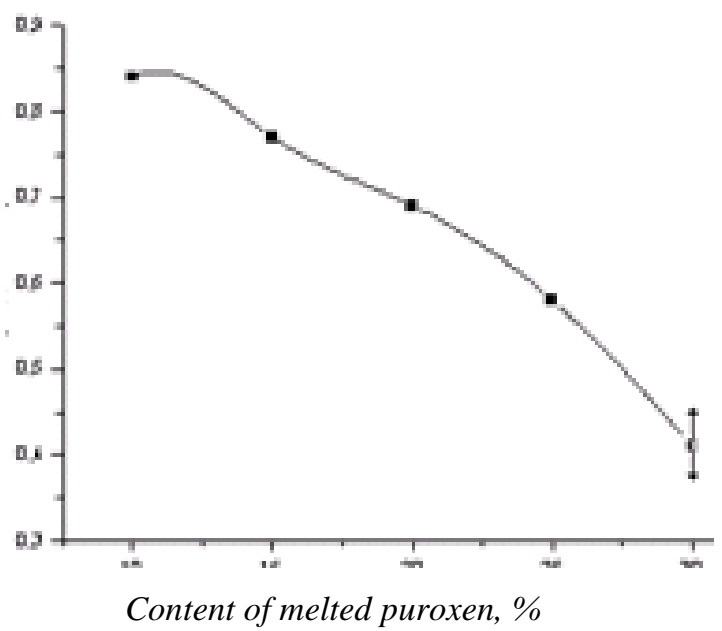

Fig7. The change of compressive strength depending on the amount injected melted pyroxene.

In the third phase of experiments diopside phase synthesized from pure silicon oxides, calcium and magnesium methods of solid-phase reactions (a) and melt-synthesis (B). The analysis showed that in the case of (a) material was diopside crystal phase, in case (b), the material along with the crystalline phase contains diopside and also glass phase (5\%). The mechanical properties of the material obtained from the pure oxides methods of solid-phase reactions (a) and synthesis from a melt (b) slightly below those of the material obtained from waste pyroxene. These data are shown in the table.

Table. Mechanical properties of the glass-ceramic material, obtained by different methods.

\begin{tabular}{|c|c|c|c|c|c|}
\hline $\begin{array}{c}\text { The method of } \\
\text { synthesis }\end{array}$ & $\begin{array}{c}\text { Phase } \\
\text { composition }\end{array}$ & $\begin{array}{c}\text { Grain } \\
\text { size, } \mathrm{nm}\end{array}$ & $\begin{array}{c}\text { Compressive } \\
\text { strength } \mathrm{MPa}\end{array}$ & $\begin{array}{c}\text { Durability, } \\
\mathrm{g} / \mathrm{cm}^{2}\end{array}$ & $\begin{array}{c}\text { The coefficient of } \\
\text { thermal } \\
\text { expansion, } 1 /{ }^{0} \mathrm{C}\end{array}$ \\
\hline $\begin{array}{c}\text { Solid phase } \\
\text { synthesis of a } \\
\text { mixture of pure } \\
\text { oxides }\end{array}$ & Crystal & $\begin{array}{c}140- \\
500 \\
\mathrm{HM}\end{array}$ & 98 & 0,04 & $1,4 \times 10^{-6}$ \\
\hline $\begin{array}{c}\text { Synthesis of the } \\
\text { melt mixture of } \\
\text { pure oxides }\end{array}$ & $\begin{array}{c}\text { Crystal + 5\% } \\
\text { glaze phase }\end{array}$ & $\begin{array}{c}120- \\
330\end{array}$ & 132 & 0,03 & $1,6 \times 10^{-6}$ \\
\hline $\begin{array}{c}\text { Synthesis of } \\
\text { Melt-pyroxene } \\
\text { new waste }\end{array}$ & $\begin{array}{c}\text { Crystal }+8 \% \\
\text { glaze phase }\end{array}$ & $\begin{array}{c}60- \\
160\end{array}$ & 145 & 0,02 & $1,7 \times 10^{-6}$ \\
\hline
\end{tabular}

As shown in [3] the residual glass phase in the crystallized fibers limits the growth of crystals in time. At the same time the residual glass phase, serves as a "buffer", contributing to the relaxation occurring during crystal growth stresses and limit the freedom of the crystal growth. It was also revealed that a significant impact on the strength of the ceramic microstructure has: the proportion of crystalline 
phase content and the glass phase composition, grain size, porosity. Increasing the crystalline phase content and decreasing grain size leads to increased strength.

Thus, the analysis of the results shows that in the synthesis of pyroxene material in concentrated solar radiation field from a melt at temperatures greater $T_{m}(350-450 \mathrm{~W} / \mathrm{cm} 2$ current density) is realized homogenous microstructural condition in combination of amorphous and crystalline phases, providing high values of mechanical properties material that can be used for the manufacture of products which have a high resistance to abrasion and the appearance of cracks at non-uniform local heating [8].

\section{REFERENCES}

[1] Matrenib S., Slosman A. The technical ceramics. Tomsk, 2004. 75 p.

[2] P.W.McMillan. Glass-Ceramics. Academic, New York 1964 Gorlov Yu. The technology of thermal insulation and acoustic materials and products. Moscow, 1989.- 384 p.

[3] Bojenov P., Holopova L. Colored cements and their use in construction. Leningrad. 1968. - 142 p.

[4] Betehtin A. Coloration and Luminescence of minerals. Moscow. 1965. - 115 p.

[5] Martynov M. Ceramic paint production technology. Kiev, 1979. - 116 p.

[6] Maslenikova G., Mamadze P. Ceramic materials. Moscow, 1991. - 412 p.

[7] Donskoy A. Electroheat. Leningrad. 1961.16p

[8] Patent RU number JAP 2009 - 0027 Glass for glass-ceramic material

\section{AUTHORS' BIOGRAPHY}

Atabaev Ilham Gafurovich, Doctor of Physical and Mathematical Sciences, Professor, Director of the Institute of Materials NGO "Physics-Sun" And Uzbekistan.

Research interests: physics of semiconductors and dielectrics, materials, superconductors and ferroelectric materials, the synthesis of materials with the use of solar energy.

Faiziev Shavkat Ph.D., deputy director of the Institute of Materials NGO "Physics-Sun" And Uzbekistan.

Research interests: optics, solar, materials, synthesis of materials with the use of solar energy.

Payzullahanov Muhammad Sultanhan, Candidate of Physical and Mathematical Sciences, Senior Research Fellow of the Institute of Materials NGO "Physics-Sun" And Uzbekistan.

Research interests: Radiation solid state physics, materials, superconductors and ferroelectric materials, the synthesis of materials with the use of solar energy. 